Vol. 5, No. 02; 2021

ISSN: $2581-3366$

\title{
3D Vector Reconstruction of the Cerebellum from Anatomical Sections of Korean Visible Human at the Clinical and Digital Anatomy Laboratory of Paris Descartes University
}

\author{
Mariam Daou ${ }^{1,2,3 *}$, Abdoulaye Kanté ${ }^{1,2,}$ Hassan Brahima Diallo ${ }^{3}$, Jean François Uhl ${ }^{1}$, Park JS ${ }^{4}$, \\ Youssoufa Maïga ${ }^{3}$, Nouhoum Ongoïba ${ }^{2}$. \\ ${ }^{1}$ Anatomy Laboratory, University of Paris 5, Paris, France. \\ ${ }^{2}$ Laboratory of Anatomy, University of Sciences, Techniques and Technologies of Bamako, \\ Mali. \\ ${ }^{3}$ Department of Neurology, CHU Gabriel Touré in Bamako, Mali. \\ ${ }^{4}$ Department of Anatomy, Donguk University School of Medicine, Republic of Korea. \\ * Correspondent: Dr DAOU Mariam, Department of Neurology at CHU Gabriel Touré in \\ Bamako, Mali. 0022366629611
}

doi: 10.51505/ijmshr.2021.5201

URL: http://dx.doi.org/10.51505/ijmshr.2021.5201

\begin{abstract}
Aim: Carry out a 3D vector reconstruction of the cerebellum from the anatomical sections of the "Korean Visible Human" for educational purposes.

Materials and Methods: The anatomical subject was a 33-year-old Korean man who died of leukemia. He was $164 \mathrm{~cm}$ tall and weighed $55 \mathrm{kgs}$. This man donated his body to science.

Her body was frozen and cut into several anatomical sections after an MRI and a CT scan. These anatomical sections were made using a $0.2 \mathrm{~mm}$ thick cryomacrotome. Thus 8,100 sections were obtained.

A segmentation by manual contouring of the different parts of the cerebellum on anatomical sections 500 to 720, was done using Winsurf version 3.5 software on a laptop PC running Windows 10 equipped with an 8 gigabyte RAM.

Results: Our 3D vector model of the cerebellum is easily manipulated using the Acrobat 3DPDF interface. The different parts of the cerebellum accessible in a menu can be displayed, hidden or made transparent, and 3D labels are available as well as educational menus for learning anatomy.

Conclusion: This reconstruction of the cerebellum constitutes a remarkable educational tool for the anatomical study of the cerebellum and can also be used as a 3D atlas for simulation purposes for training in therapeutic gestures.
\end{abstract}

Keywords: Three-dimensional anatomy; Korean human visible; Modeling of the cerebellum; Virtual reality; 3D reconstruction; Virtual dissection; Surgical simulation; Surgical training 


\section{International Journal of Medical Science and Health Research}

Vol. 5, No. 02; 2021

ISSN: 2581-3366

\section{1-Introduction}

Training in human anatomy is essential at all stages of medical practice: clinical examination, interpretation of medical images and surgery are based on knowledge of the anatomy of the human body. The acquisition of these skills is first theoretical and then practical with dissection. Unfortunately, the provision of subjects for this stage of learning by dissection remains problematic, in general in countries of the South and in particular in Mali, sometimes leaving certain professionals to start their careers with little experience in this field.

Sectioned images of the human body are very useful because of their high resolutions and natural colors compared to CT scans and magnetic resonance imaging [1]. The images available include those from the Visible Human Project (VHP, male and female) conducted in the United States [1]; the "Visible" Chinese human (CVH, male and female) [2]; the Chinese virtual human (VCH, man and woman) [3]; and the Korean "Visible female (VK; full male body, male head, and female pelvis) [4].

The sectioned images of the VHP, CVH and VK males were used in several ways: for the creation of atlases [5], navigation software [6,7] and virtual dissection software [8] and allowed access free and free to three-dimensional models in atlas PDF files [7,9]. In addition, crosssectional images of $\mathrm{VK}$ were used so that the radiology dose conversion coefficients are calculated virtually [10]. However, the use of the prepared female sectional images has been limited for the following reasons:

- In VHP images, degeneration of the uterus and ovaries was observed because the subject was post-menopausal (59 years), and the lateral edges of the two arms could not be used due to the subject's overweight.

- The image quality was not optimal due to the limited performance of the digital camera and the personal computer used $[11,12]$.

- In addition to this, gaps in the images appeared in the digital atlases.

In $\mathrm{CVH}$ and $\mathrm{VCH}$ images, small pixel size (> 1mm) and 24-bit color images were taken, but the colors of the living body could not be represented because a fixer had been injected into the body and a red dye had been infused into the arteries [13]. If there were high-quality sectional images of a whole male body, they would be very useful, like images of female bodies.

It is in this context, that we initiated this work in order to reconstruct the cerebellum from the anatomical sections of Korean Visible Human. (KVH)

\section{Materials and Methods:}

Our study was carried out from April 11 to July 12 in the Research Unit in Development, Imaging, Anatomy (URDIA) EA 4465 at the Laboratory of Clinical and Digital Anatomy of Paris Descartes University. 


\section{International Journal of Medical Science and Health Research}

Vol. 5, No. 02; 2021

ISSN: 2581-3366

Anatomical sections of a 33-year-old Korean man who died of leukemia who donated his body were taken in 2010 after an MRI and CT scan. A cryomacrotome made it possible to make 0.2 $\mathrm{mm}$ thick sections on the frozen body, ie 8100 sections. (Figures 1: showing the photographs of the anatomical sections of the $\mathrm{KVH}$ )

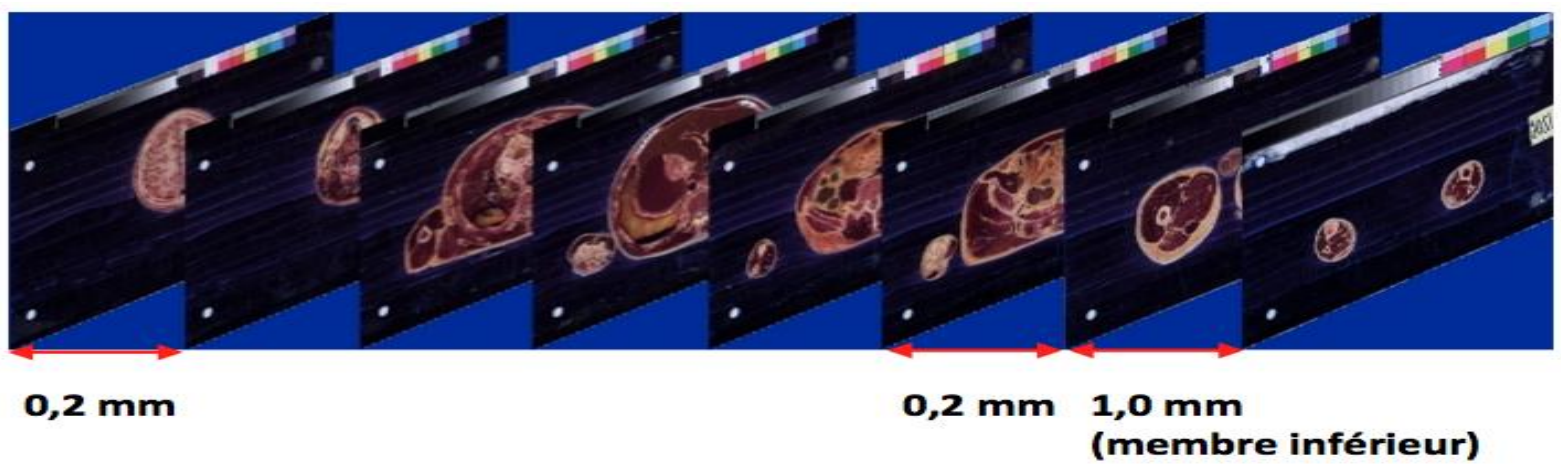

Figure 1: Showing the photographs of the anatomical sections of the KVH

We performed the contours on the sections numbered 500 to 720

(Figure 2): horizontal anatomical (2D) sections passing through the cerebellum).
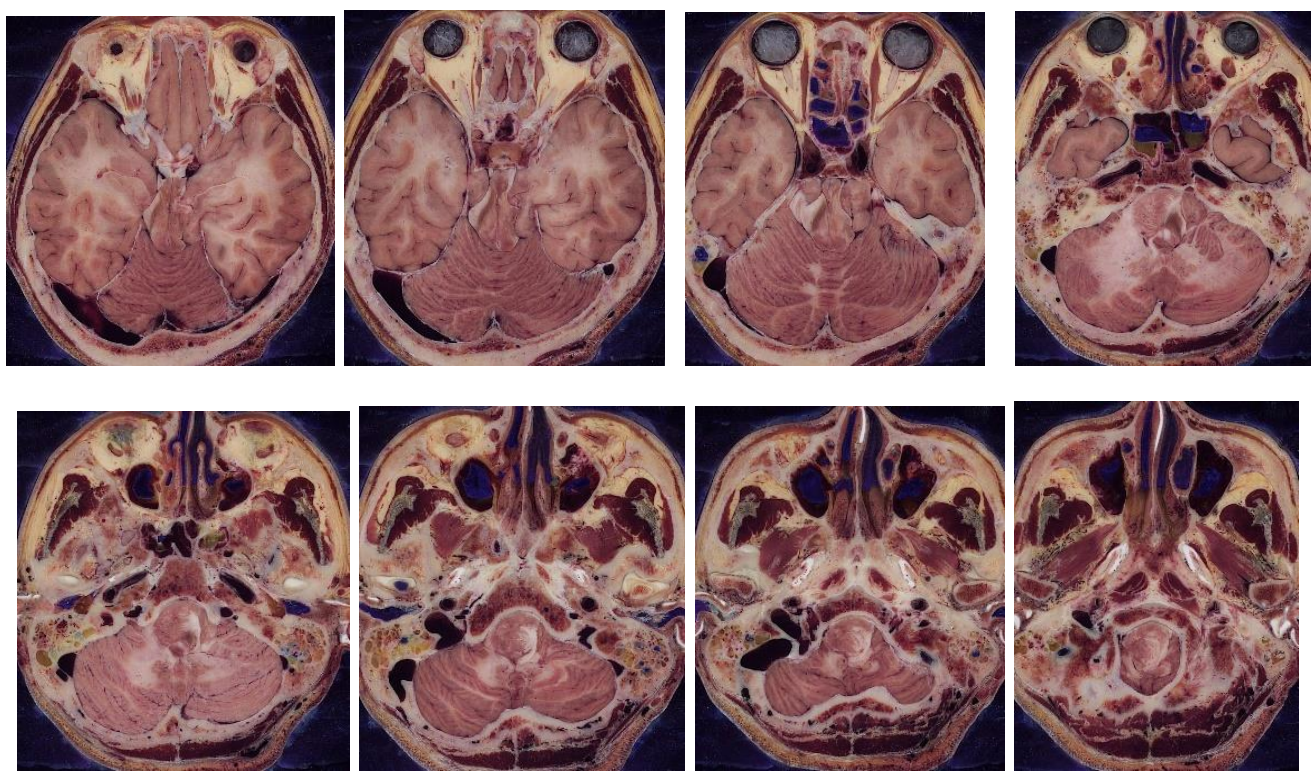

Figures 2: horizontal anatomical sections (2D) passing through the cerebellum.

Segmentation by manual contouring of the different parts of the cerebellum was done using the Winsurf version 3.5 software on a laptop PC running Windows equipped with an 8 gigabyte Ram (Figure 3 showing the contouring on section number 550) 


\section{International Journal of Medical Science and Health Research}

Vol. 5, No. 02; 2021

ISSN: 2581-3366

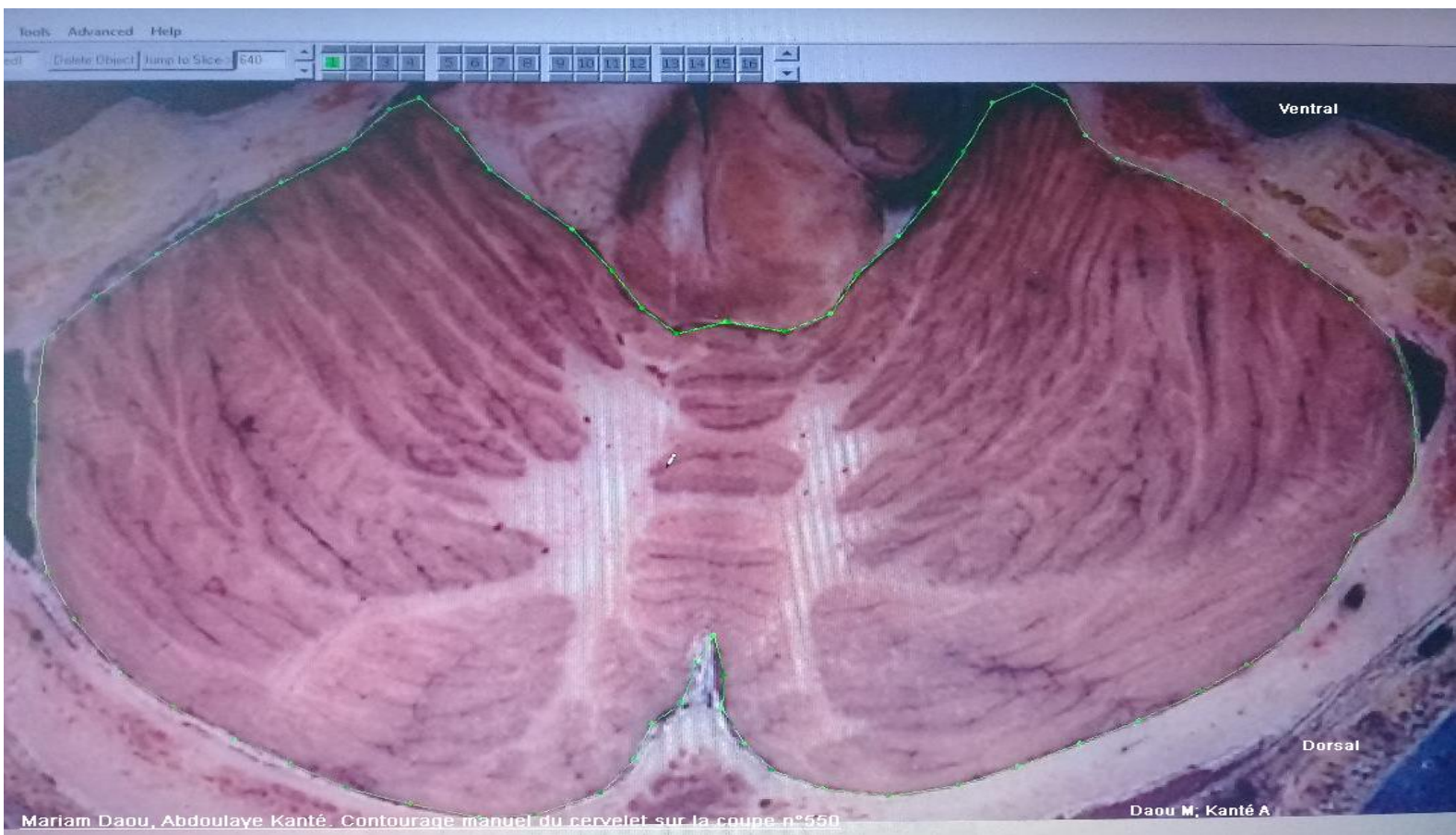

Figures 3: Winsurf® software interface screen (version 3.5) to draw the boundaries of the cerebellum (green line and dots) on anatomical slice number 550 this is done with the pen tool using the green channel.

\section{Result}

Our methodology allowed us to perform 3D vector reconstruction of the cerebellum. Here are the different presentations of the cerebellum as it is taught to students.

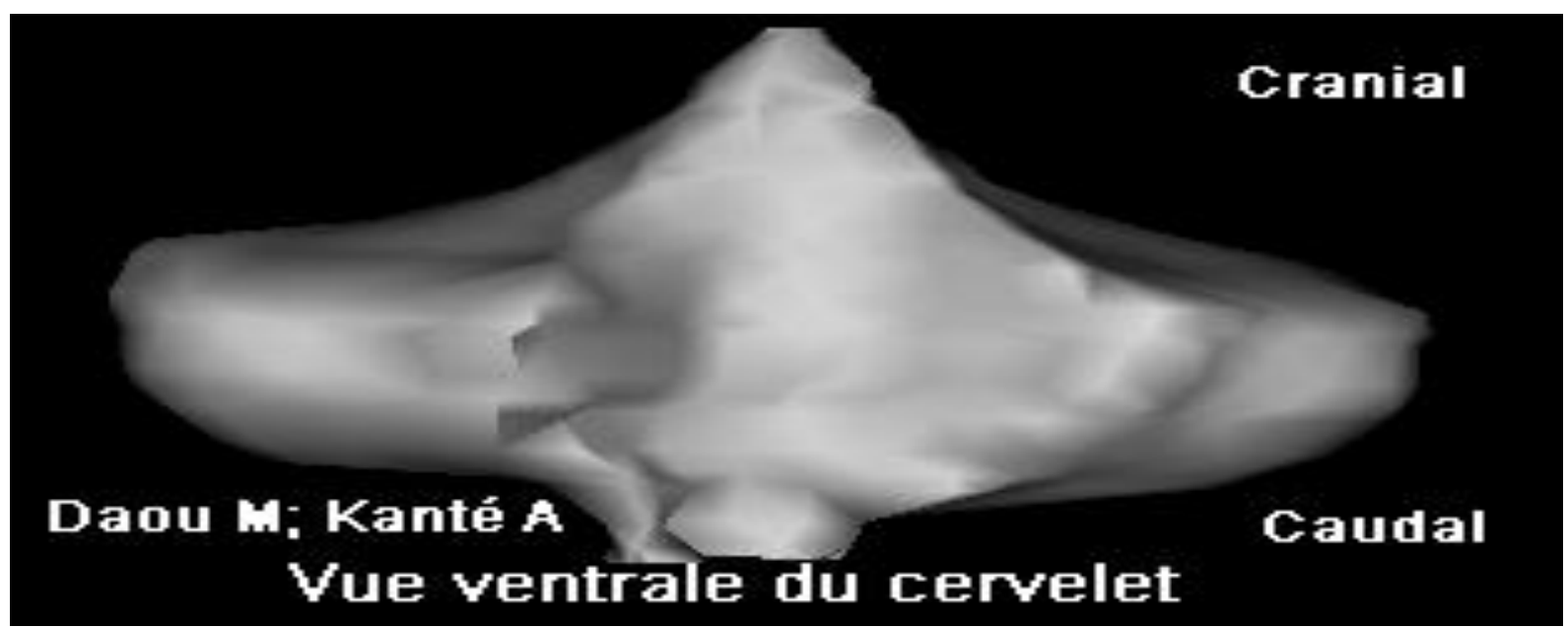

Figure 4: 3D vector reconstruction of the cerebellum with the Winsurf software: ventral view 


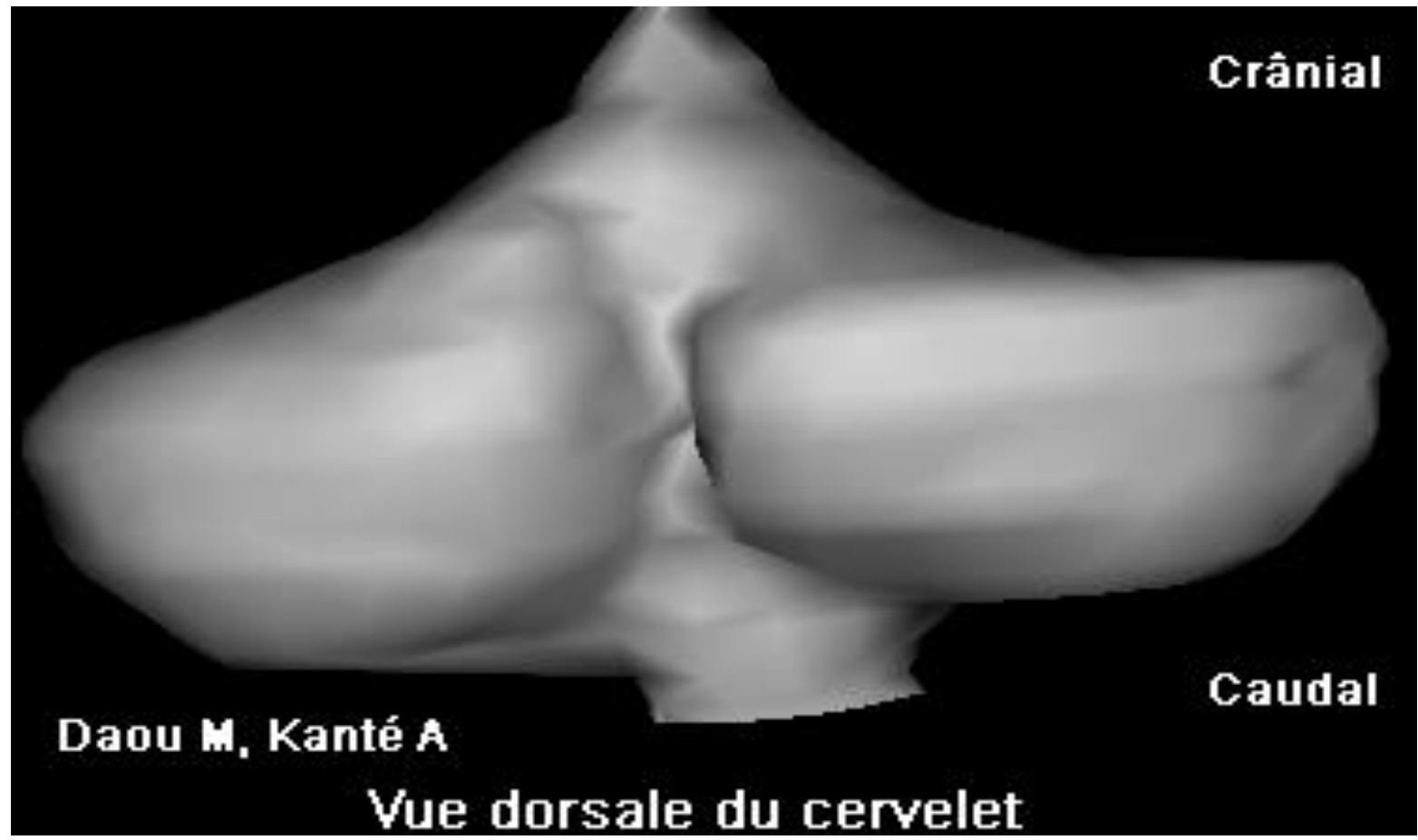

Figure 5: 3D vector reconstruction of the cerebellum using Winsurf software: dorsal view

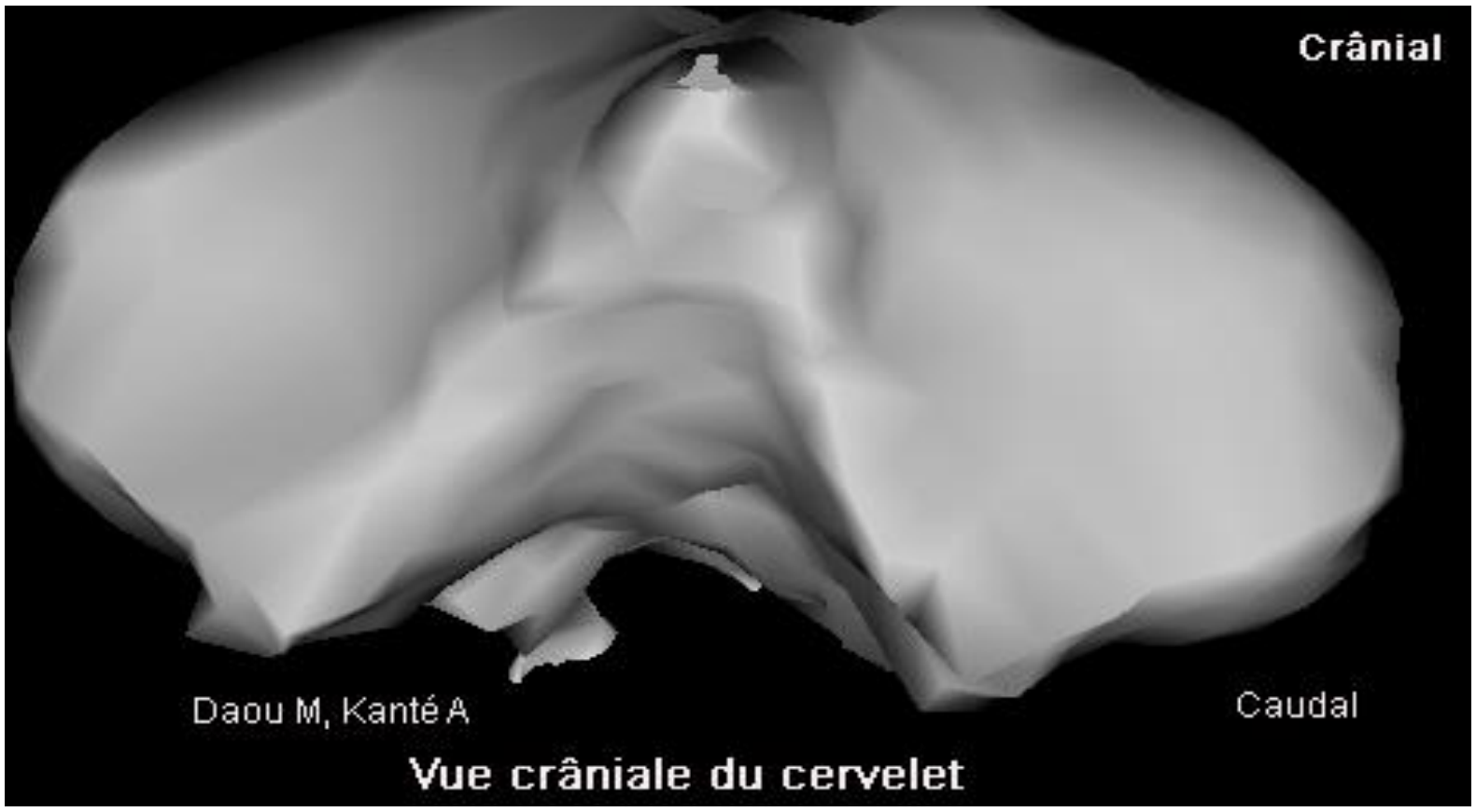

Figure 6: 3D vector reconstruction of the cerebellum with the Winsurf software: cranial view 
International Journal of Medical Science and Health Research

Vol. 5, No. 02; 2021

ISSN: 2581-3366

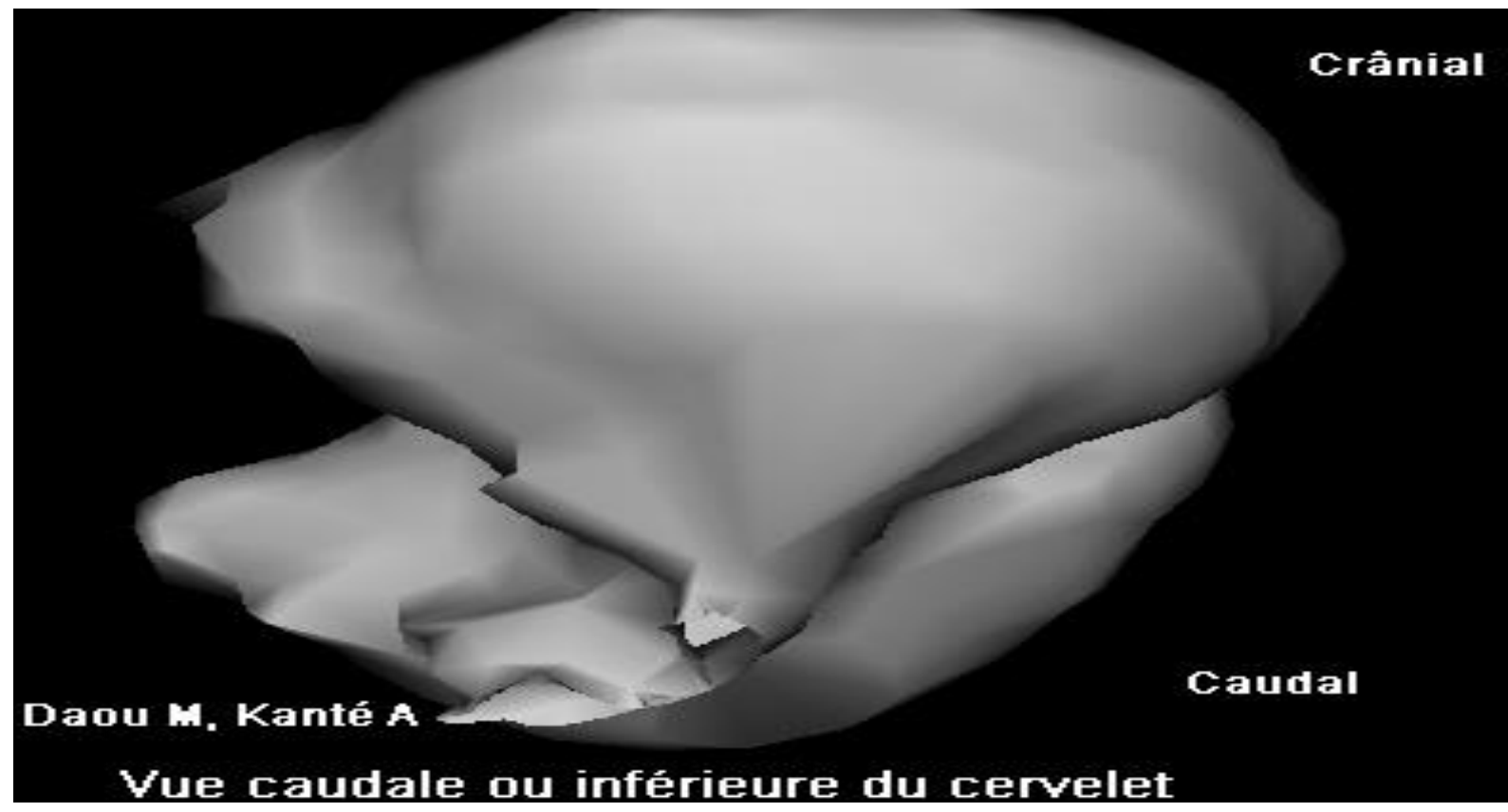

Figure 7: 3D vector reconstruction of the cerebellum with the Winsurf software: caudal view

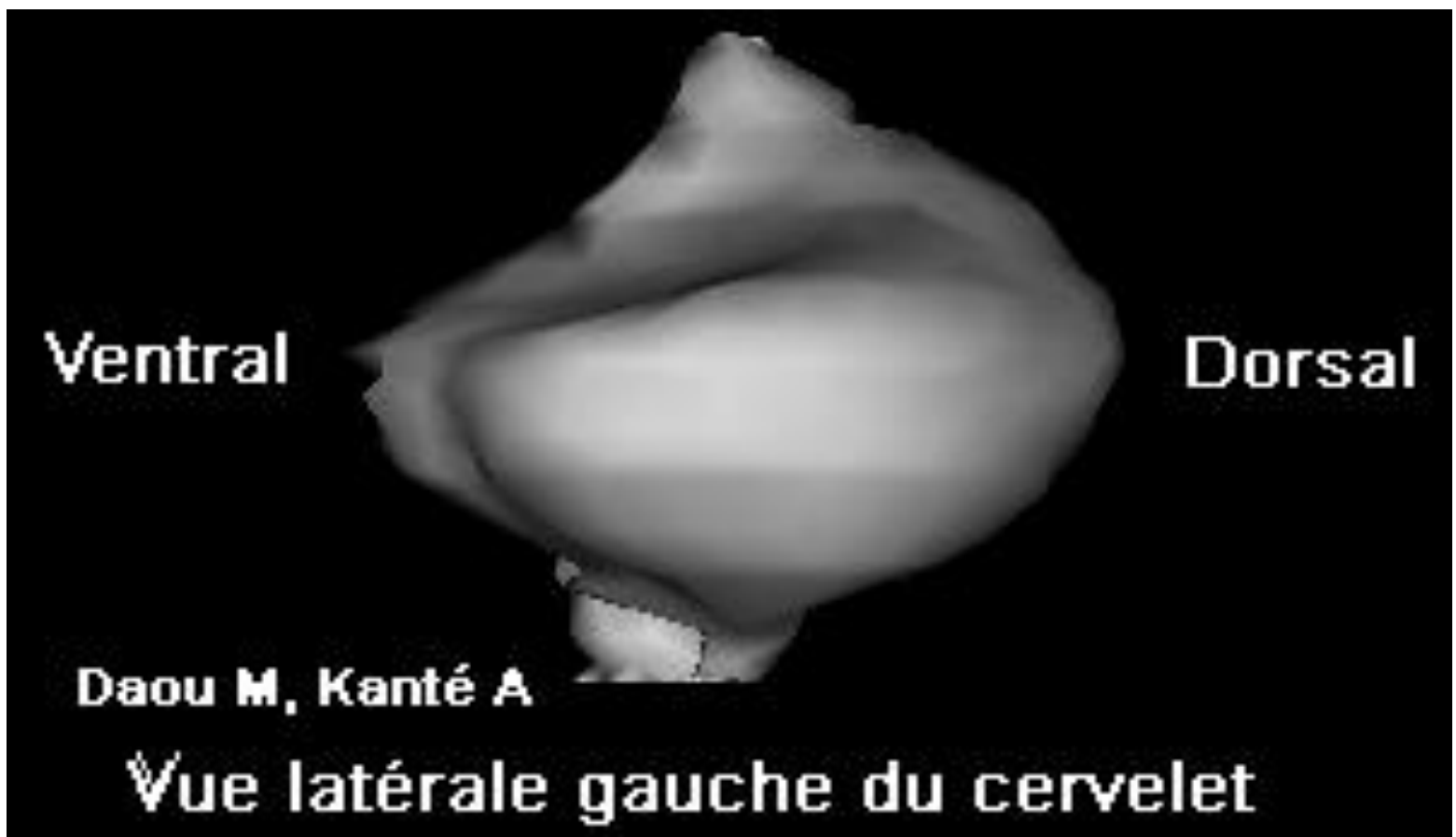

Figure 8: 3D vector reconstruction of the cerebellum using Winsurf software: left lateral view 
International Journal of Medical Science and Health Research

Vol. 5, No. 02; 2021

ISSN: 2581-3366

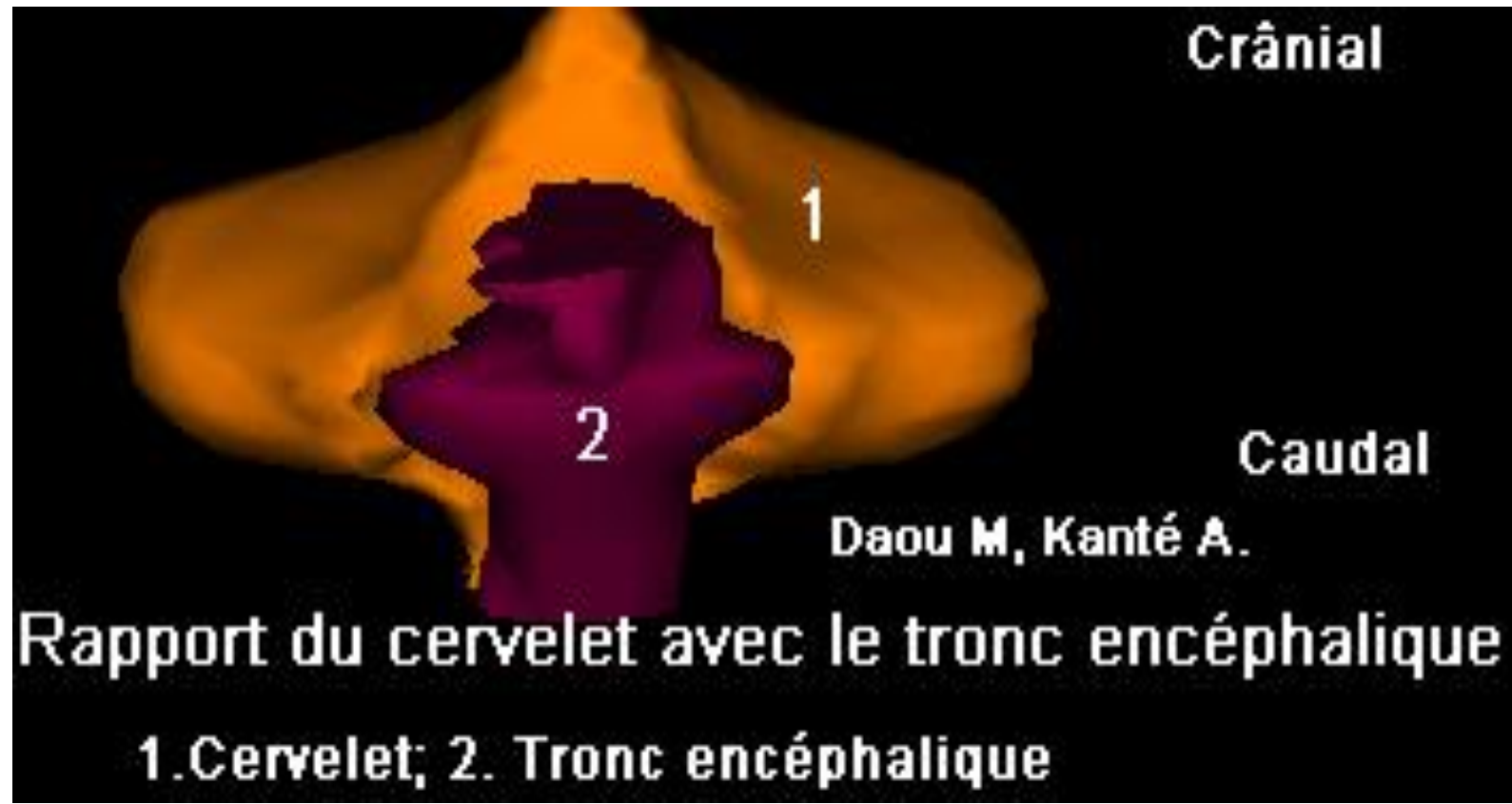

Figure9: Ratio of the cerebellum to the brainstem. Ventral view

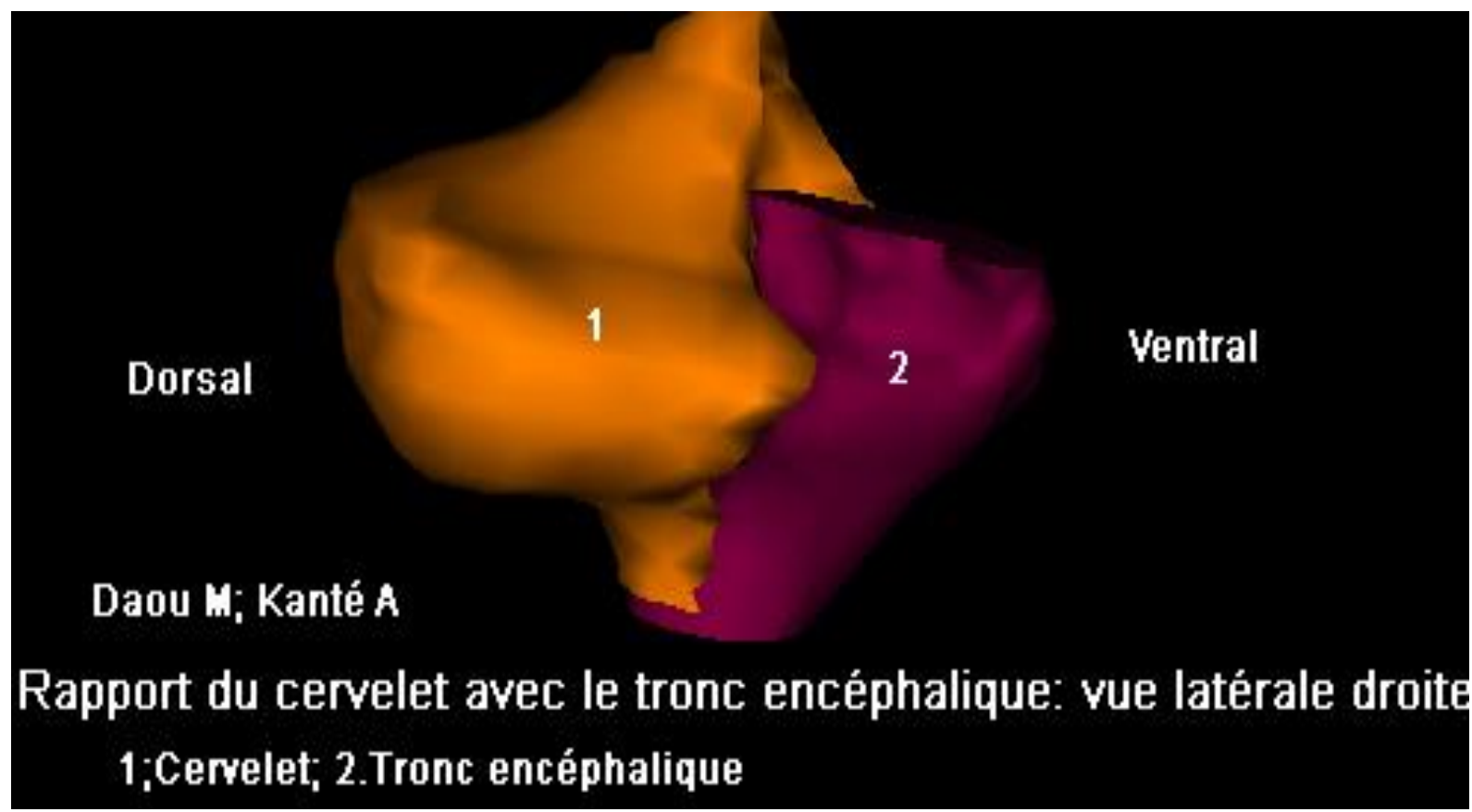

Figure 10: Ratio of the cerebellum to the brainstem. Right side view 


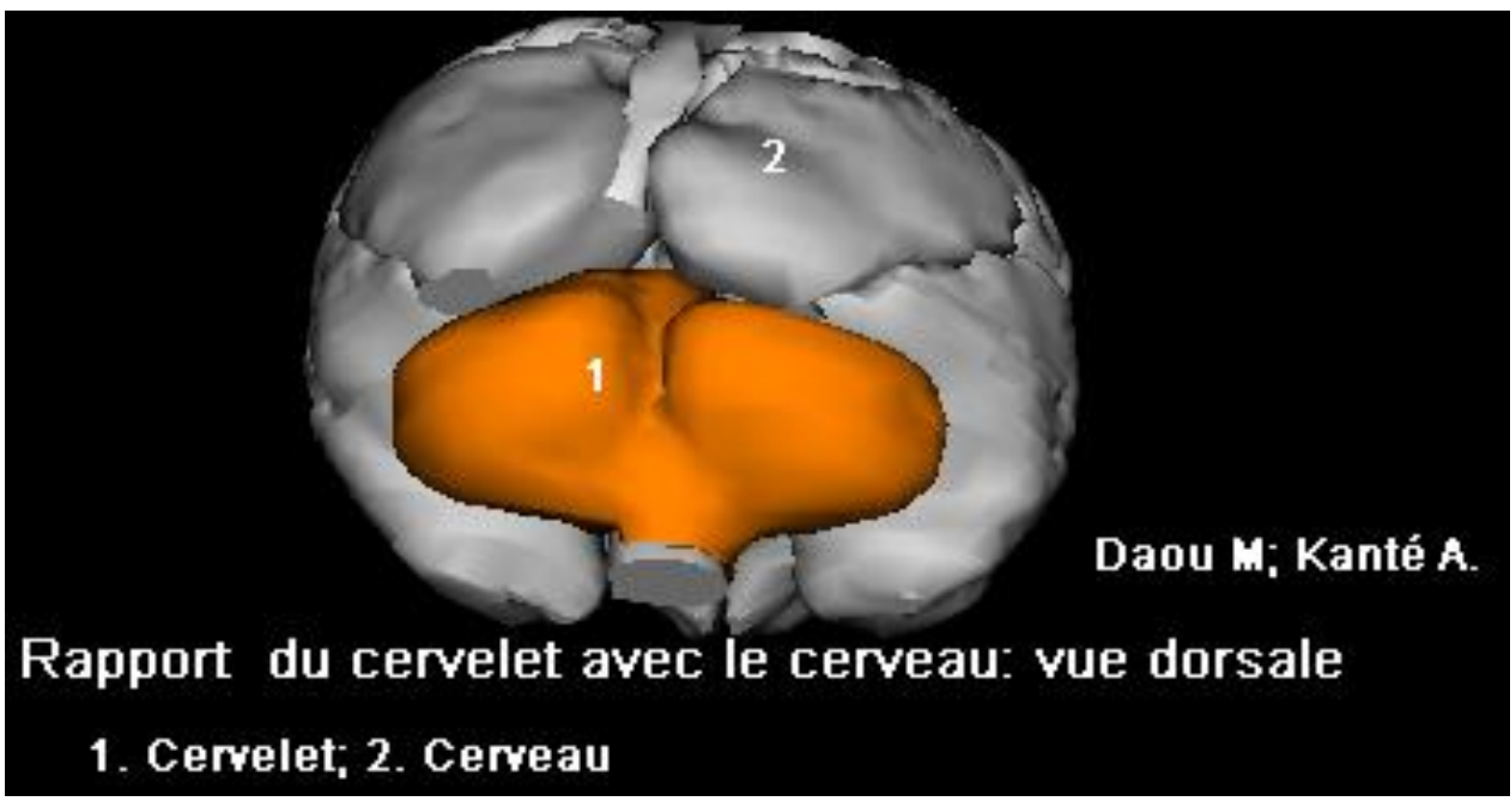

Figure 11: relationship of the cerebellum to the brain. Dorsal view

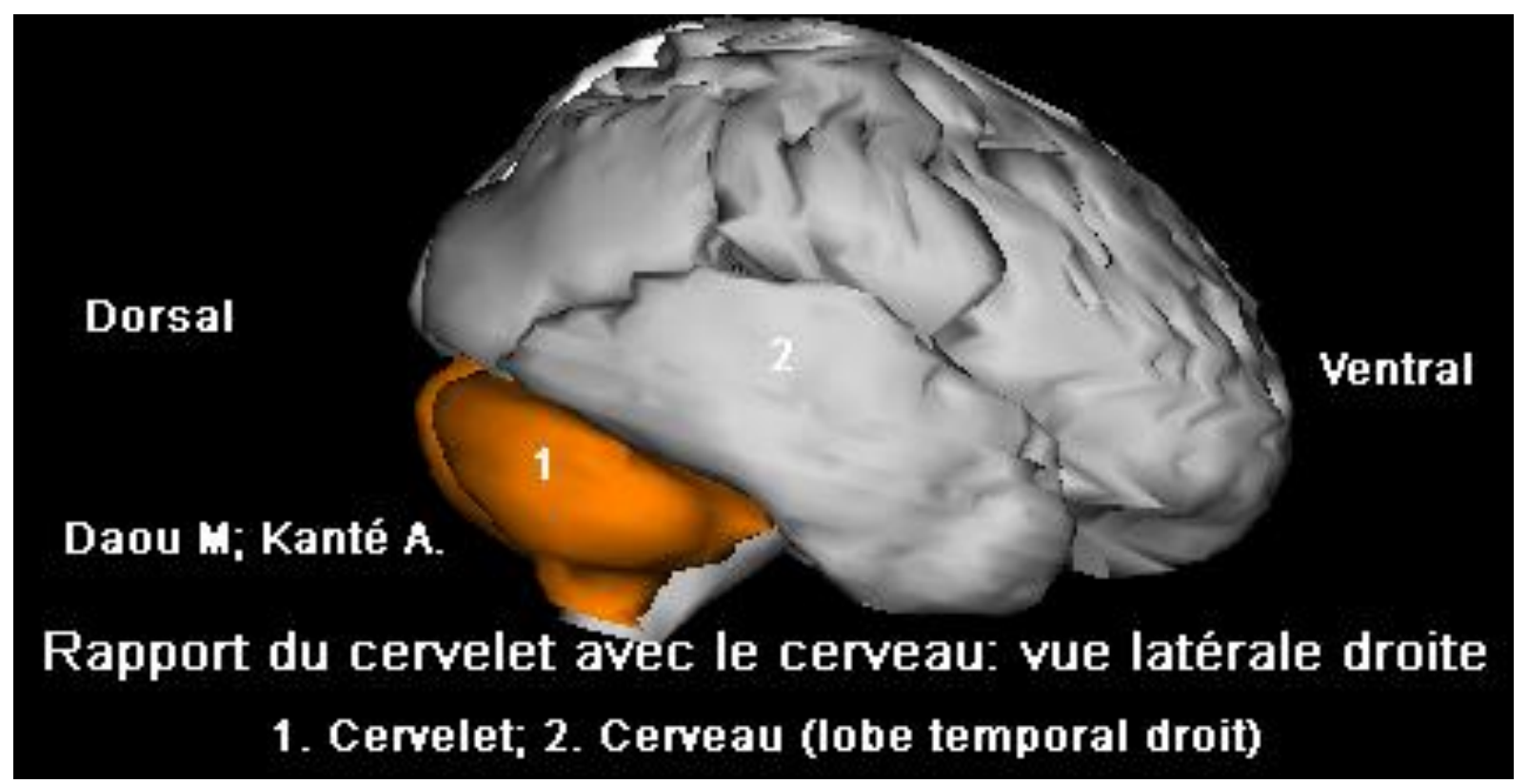

Figure 12: relationship of the cerebellum to the brain. Right side view 


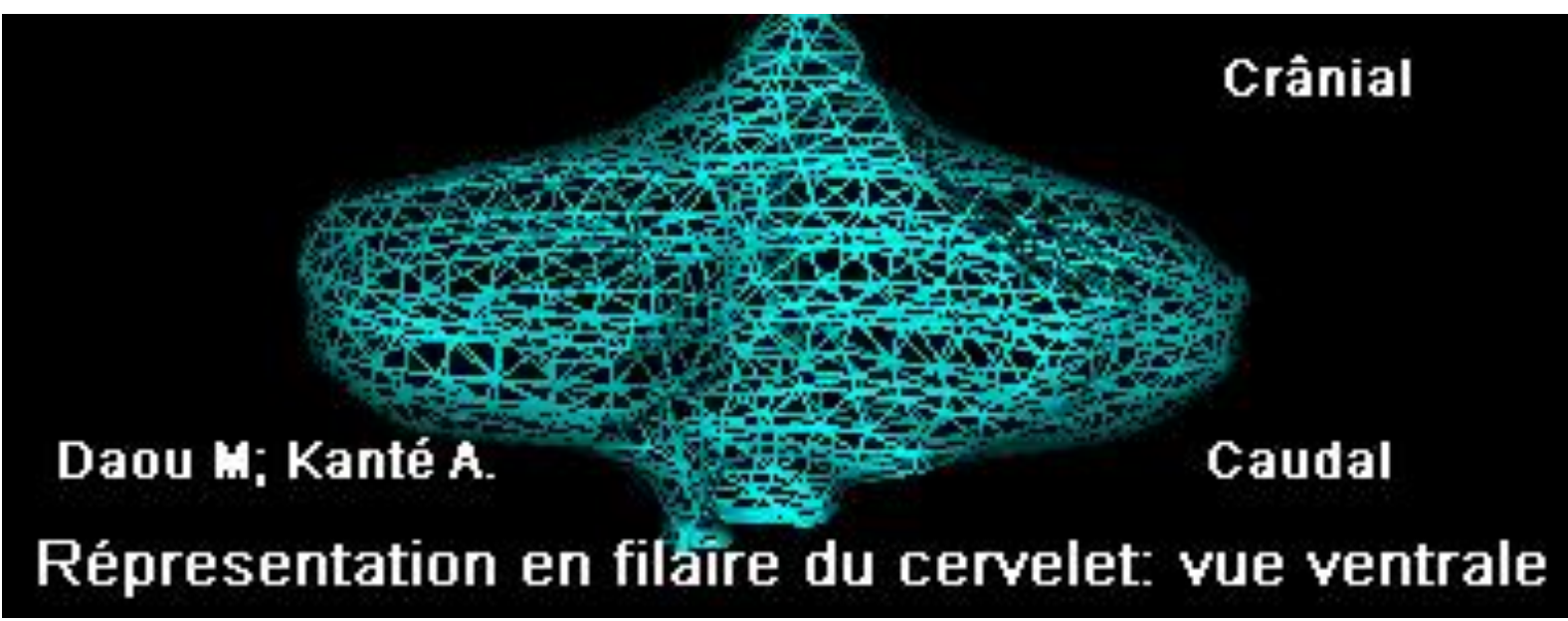

Figure 13: 3D vector reconstruction of the cerebellum in wireframe with the Winsurf software. Ventral view

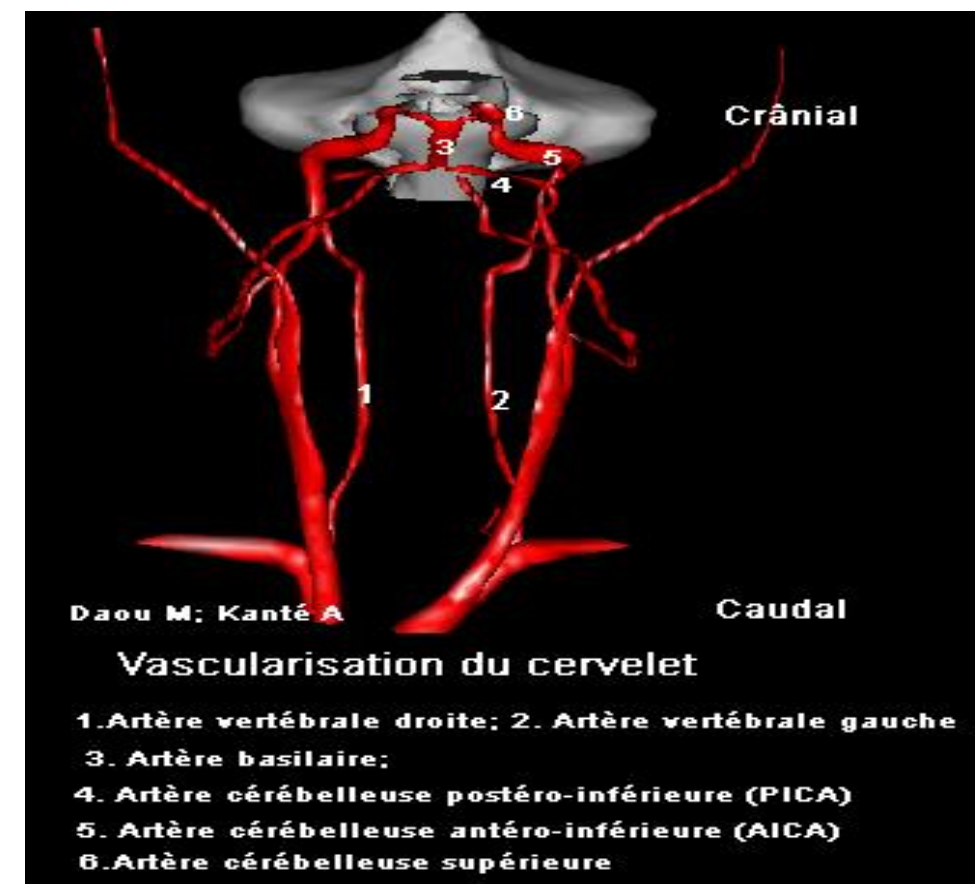

Figure 14: 3D vector reconstruction of the arteries of the cerebellum with the Winsurf software. 
Vol. 5, No. 02; 2021

ISSN: 2581-3366

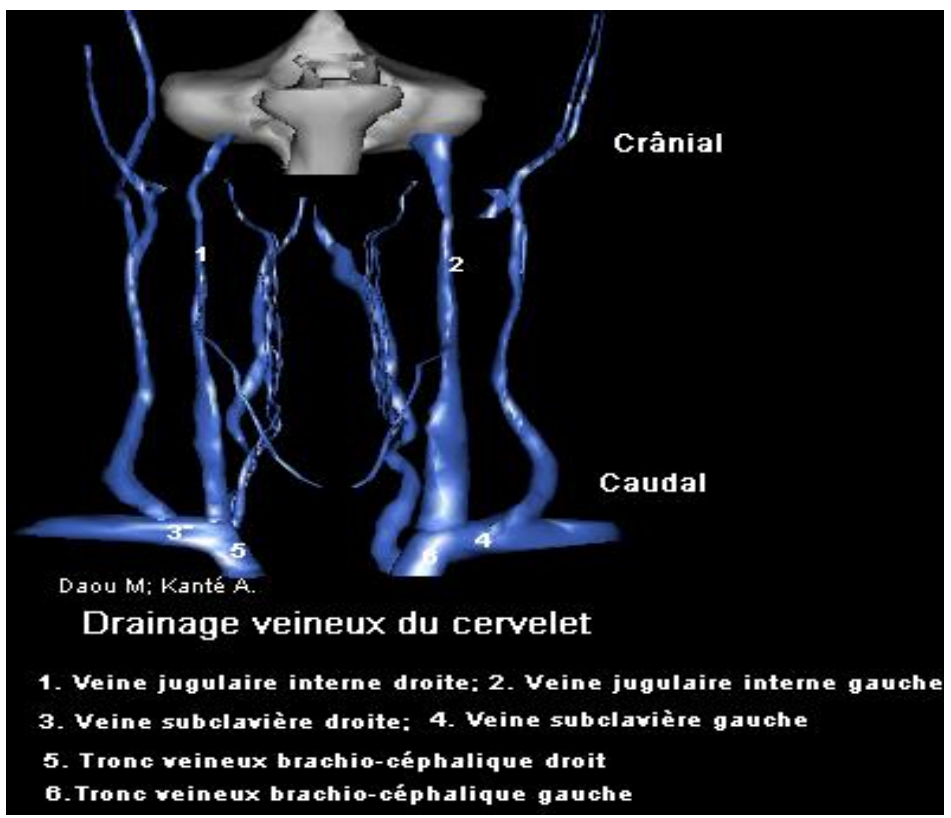

Figure 15: 3D vector reconstruction of the veins of the cerebellum with Winsurf software.

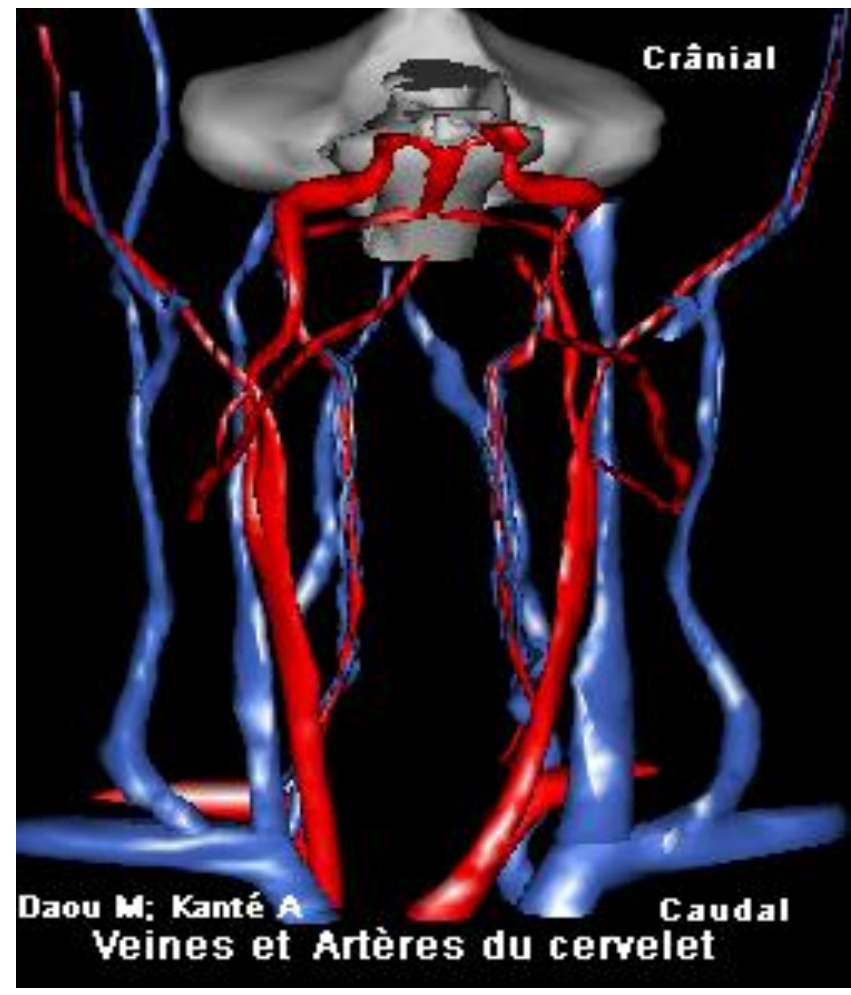

Figure 16: 3D vector reconstruction of the cerebellum veins and arteries with Winsurf software. 


\section{International Journal of Medical Science and Health Research}

Vol. 5, No. 02; 2021

ISSN: $2581-3366$

\section{4-Discussion}

This article was made from the anatomical sections of Korean Visible Human in order to achieve in the best possible way, a 3D atlas of the cerebellum, dynamic and detailed.

Our work therefore consisted in recognizing the anatomical structures of the cerebellum and in more tedious contouring work in order to obtain the most realistic models possible. Our methodology is quite similar to that of the Korean team who instead used segmentation instead of manual contouring. (Figures 17: segmented cuts used by the Korean team)
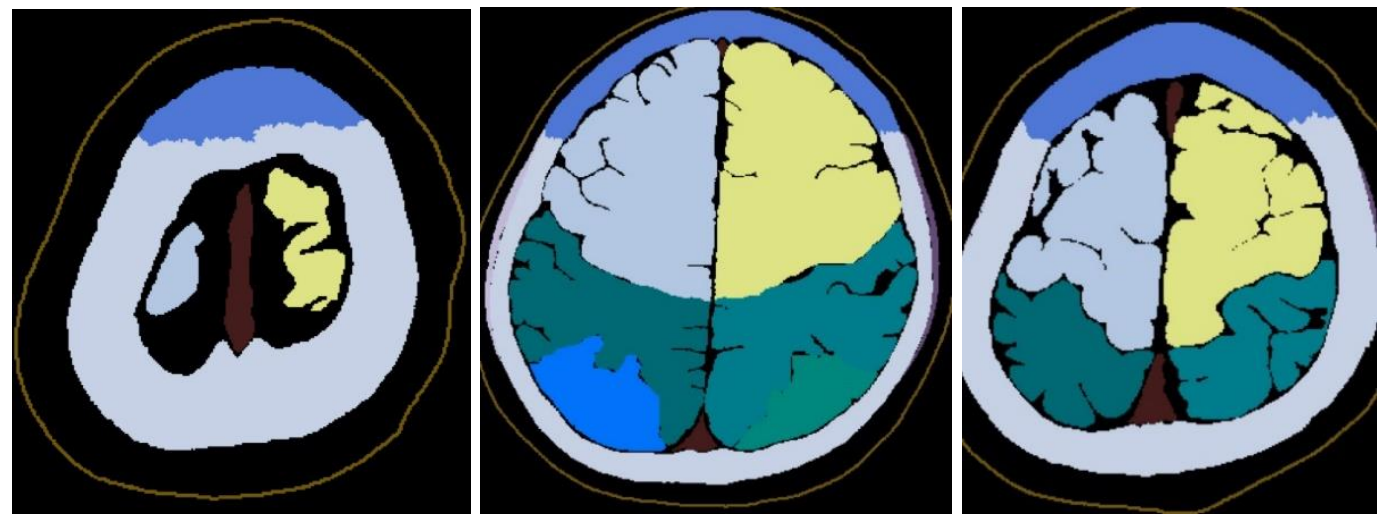

Figures 17: Segmented cuts used by the Korean team

The advantage of this work is essentially based on the fact that all of the contouring work and therefore all of the $3 \mathrm{D}$ vector reconstruction of the cerebellum was made from real sections of the human body. The result is a major increase in the precision and reliability inherent in the results presented above.

Indeed, reconstructions of the cerebellum using digital procedures such as CT scans can be somewhat disappointing in that some structures are absent and others that are difficult to distinguish. As opposed to this process, this contouring work relies on a process of manual, analog segmentation under our supervision and not by that of an automaton, which reduces the risk of anatomical errors in the reconstruction.

The second advantage is based on the fact that better precision as well as the possibility of individualization of the different parts of the cerebellum favors a massive application in the academic field thus contributing to a better understanding by the students of medicine and other fields. In addition, it is essential to underline that this application is not restricted to the university field but can also be the support of a "Surgical Training" thus allowing a continuous training of the surgeons and a fortiori an improvement of their aptitude in their practices daily.

Finally, it is clear that "Winsurf" and Acrobat 3D PDF are particularly easy to learn software, which is not the case with other 3D modeling and manual segmentation software. In addition, 


\section{International Journal of Medical Science and Health Research}

Vol. 5, No. 02; 2021

ISSN: $2581-3366$

they offer fairly wide ranges of textures which further increase the realism that we can bring to our final work.

Although the "Winsurf" software made it possible to reproduce the cerebellum fairly faithfully, it still has some flaws.

The main disadvantage of this software is the length of work required to achieve the desired result. Indeed, it is a tedious contouring work of several months on several anatomical sections where sometimes only the cut-by-cut analysis was possible. To this are added the various objects that had to be created in order to be able to individualize the edges of the cerebellum, which increased tenfold the number of cuts to which it was necessary to come-back each time.

Unfortunately, there is no miracle cure allowing a reduction of this working time if it is not a great motivation and an unprecedented personal investment.

Conclusion: our 3D vector model of the cerebellum constitutes a remarkable educational tool for teaching the anatomy of the cerebellum and can also serve as a $3 \mathrm{D}$ atlas for simulation purposes for training in therapeutic gestures.

\section{Conflicts of interest:}

The authors declare no conflict of interest regarding the publication of this document.

\section{References}

1.Ackerman M. J. The Visible Human project. A resource for education. Acad Med.199;74(6):667-70.

2.Cho Z. H. 7.0 Tesla MRI Brain Atlas, In Vivo Atlas with Cryomacrotome Correlation. Springer, New York.2009.

3.Cho Z. H; Calamate F; Chi JG. 7.0 Tesla MRI brain white matter atlas. Panmun, Seoul.2012.

4.Chung BS; Shin DS; Brown P; Choi J; Chung MS. Virtual dissection table including the Visible Korean images, complemented by free software of the same data. Int J Morphol. 2015;33(2):440-45.

5.Dai JX; Chung MS; Qu RM; Yuan L; Liu SW; Shin DS. The Visible Human Projects in Korea and China with improved images and diverses applications. Surg. Radiol. Anat. 2012;34(6):527-34.

6.Kim CH; Choi SH; Jeong JH; Lee C; Chung MS; HDRK-Man. A whole-body voxel model based on high-resolution color slice images of a Korean adult male cadaver. Phys Med Biol.2008;53(15):4093-106.

7.Park HS; Chung MS; Shin DS; Jung YW; Park JS. Accessible and informative sectioned images, color-coded images, and surface models of the ear. Anat Rec.2013;296 (8):118086. 
Vol. 5, No. 02; 2021

ISSN: 2581-3366

8.Park JS; Chung MS; Hwang SB; Lee YS; Har DH; Park HS. Visible Korean Human: Improved serially sectioned images of the entire body. IEEE Trans. Med. Imaging. 2005;24 (3):352-60.

9. Park JS; Chung MS; Hwang SB; Lee YS; Har DH; Park HS. Technical report on semiautomatic segmentation by using the Adobe Photoshop. J Digit Imaging.2005;18 (4):333-43.

10.Park JS; Chung MS; Hwang SB; Shin BS; Park HS. Visible Korean Human: Its techniques and applications. Clin Anat. 2006;19(3):216-24.

11.Park JS; Chung MS; Shin DS; Har DH; Cho Z.H; Kim YB; Han JY; Chi J.G. Sectioned images of the cadaver head including the brain and correspondences with ultrahigh field 7.0 T MRIs. Proc IEEE.2009;97 (12):1988-96.

12.Quackenbush D; Ratiu P; Kerr,J. Segmentation of the Visible Human Data Sets.The Visible Human Project Conference Proceedings. October 1996:7-8.

13.SchiemannT; Freudenberg J; Pflesser B; Pommert A; Priesmeyer K; Riemer M; Schubert R; Tiede U; Höhne KH. Exploring the Visible Human using the VOXEL-MAN framework. Comput Med Imaging Graph.2000;24(3):127-32. 